\title{
Fieldwork after conflict: contextualising the challenges of access and data quality
}

Kate Roll Lecturer in Empirical Politics, Somerville College, University of Oxford, United Kingdom, and Geoffrey Swenson Lecturer, Department of International Politics, City, University of London, United Kingdom

Despite sustained scholarly interest in post-conflict states, there has not been a thorough review and analysis of associated methodology and the challenges of conducting research in these contexts. Addressing this gap, this paper directs attention to the particular effects of these settings on access and data quality and their ramifications for the resulting scholarship. It assesses the intrinsic challenges of performing fieldwork in these environments, drawing on both relevant social science literature and the authors' experiences of carrying out research in Afghanistan and Timor-Leste. The study demonstrates that the post-conflict environment moulds research design and, consequently, influences how questions are answered as well as the questions asked. Moreover, it highlights ways to mitigate these issues. This work is of relevance to scholars planning to engage in field research and to researchers reflecting upon their work, as well as to policymakers who are considering undertaking programmes or commissioning research in post-conflict areas.

Keywords: Afghanistan, data quality, fieldwork, post conflict, research, qualitative methods, Timor-Leste

\section{Introduction}

The end of the Cold War in I99I sparked a steady increase in writing on post-conflict states, and, in the past decade, a florescence of micro-level, field-driven work on conflict and its effects. Scholars have produced excellent academic studies of post-conflict states that draw on intensive fieldwork to investigate issues as diverse as ex-combatant reintegration, international peace-building practices, post-conflict economies, and transitional justice. Nevertheless, general examinations of what conducting fieldwork in these settings involves and how such locales influence research design, and ultimately outputs, remain rare. This paper differs and contributes to this literature in three key ways: (i) through its focus on post-conflict environments; (ii) by introducing a broad framework for identifying the type of challenges encountered in the field; and (iii) through its focus on linking these challenges to biases in reporting.

Attention to conditions in the field, particularly how researchers from outside these contexts adjust, is of practical importance to those planning to perform field research. Fieldwork challenges are also important for understanding how post-conflict settings are studied, which is essential for those critically examining existing literature. This paper explores the connection between field conditions, research practices, and knowledge production. It responds specifically, therefore, to the call of Bush and Duggan 
(20I3, p. 6) for the 'systematic consideration and incorporation of conflict context' in research, and it echoes their acknowledgement that conflict settings, or in this case post-conflict settings, are far from 'business as usual'. Accordingly, this paper asks: what are the main constraints posed by conducting field research in post-conflict states? What biases do these issues introduce? And how do researchers adjust their work to the context? It concludes by looking at strategies for recognising and mitigating these effects and for considering the overarching question of how these contextdriven practices influence the type and scope of knowledge researchers produce.

To address the lack of a generalised evaluation of fieldwork in post-conflict environments, this paper first presents a systematised framework that identifies and describes two types of issues commonly encountered in research in post-conflict contexts: issues of access and issues of data quality - with the charged political setting as a crosscutting theme. Drawing on the experiences of the authors and taking the perspective of 'etic' field researchers not from the site or community under review, this paper approaches access pragmatically. It highlights the effects of research permission structures, degraded infrastructure and insecurity, as well as the deliberate efforts of those hostile to the programme to delimit the researcher's ability to move freely or, more abstractly, to probe certain subjects or networks - this effectively circumscribes the 'field' under review. The issue of data quality is similarly broadly conceived, encompassing issues pertaining to the common dearth of quantitative data and records, as well as assessing the effects of conflict on the capability and willingness of respondents to participate in research. Here the paper pinpoints the compounding issues of traumatisation, distrust, and research fatigue that may be found in post-conflict areas, with the latter particularly notable as compared to conflict environments. Such issues concerning data quality establish boundaries regarding how subjects can be analysed, particularly in the case of quantitative methodologies that, for instance, rely on bureaucratic data to construct sampling frameworks. Data quality issues again circumscribe the 'field'.

Finally, in addition to emphasising broad access and data quality issues, this paper makes a theoretical contribution by appraising how researchers' experiences can significantly shape the scholarship they produce. In other words, post-conflict environments have their own political economies of knowledge production. Building on the work of Chambers (2006) on international development research, the paper identifies drivers of bias, suggesting that post-conflict settings have aggregate effects on research outputs. Reflecting on the work of other scholars and the authors' own fieldwork, this paper outlines how access and data quality issues can result in fieldwork reliant on geographically limited, elite interviewing, undermining the benefits of such endeavours. Furthermore, as different methods produce different types of knowledge, these constraints and biases limit both how questions are answered and what questions are presented in the first place. How, given the difficulties of carrying out research in post-conflict contexts, can researchers work to ensure the literature's methodological diversity and rich multivocality, and to address the risk of misinterpretation? 


\section{Surveying the field}

Existing work on the challenges of research in post-conflict contexts has focused on specific methodological approaches and guiding researchers to adapt to these environments (Haer and Becher, 2012; Simons and Zanker, 2012). Within the realm of Disasters, Barakat and Elliswhich (1996, p. I56) have highlighted the need for more conversation on 'research under fire'. Non-governmental organisations (NGOs) and international organisations have likewise sought to scrutinise and improve monitoring and evaluation practices in the field. ${ }^{1}$

Moving beyond the more practice-oriented methodological literature, other authors provide on-the-ground accounts of researchers' personal fieldwork experiences by exploring how individuals cope with insecurity and stress, as well as ethical concerns (Silkin and Hendrie, I997; Angucia, Zeelen, and de Jong, 20I0; Carpenter, 20I2). The challenges of studying post-conflict and other complex environments, indeed, have been the spotlight of work in the spheres of anthropology and sociology as well (Nordstrom and Robben, I995; Schmidt and Schröder, 200I; Richards, 2005). These obstacles, however, have rarely been linked with discussions on how these experiences affect the creation of knowledge about the subject as a whole. Finally, interest has increased in recent years in the epistemic practices of conflict expertise (Kühn, 20I6) and in how conflict knowledge shapes interventions (Autessere, 20I2). In contrast, this paper lays out the constraints and challenges that configure the field for researchers and shapes their initial arena of inquiry. As such, it makes a novel contribution and begins to connect the concerns of these discrete literatures.

\section{The post-conflict context and sites of inquiry}

This paper takes as its area of investigation research in post-conflict contexts. As such, it defines post-conflict research environments broadly, building on the distinction of Cohen and Arieli (20I I, p. 475) between positive and negative peace: 'An environment of conflict is not necessarily one of actual war. Rather, it implies a wider range of adverse social situations. Similarly, the post-conflict period is characterised by a wide range of adverse political and social issues. While a peace agreement may have been signed, the legacies of violence are still dominant. We are hesitant, therefore, to draw sharp lines, such as at the decade mark, to define post-conflict periods as has been necessary in some evaluations (Collier and Hoeffler, 2006). Thus, post-conflict refers to the period where the conflict's settlement is tentative and has yet to be consolidated definitively or undermined.

The often charged and unstable political climate of post-conflict states is incorporated as a crosscutting issue in research, with implications for access and data quality. For example, even when the conflict has largely abated, struggles over narratives about the event and its outcomes remain active. To a greater degree than research in non-post-conflict settings, this study suggests that researchers may actively participate in the struggle to define the conflict and the post-conflict settlement both domestically and internationally. The researcher can become embroiled in these contests over 
the production of authoritative accounts of the conflict, its dynamics, or consequences. Such tensions may be particularly acute for local researchers examining their own communities and identity groups. Hence, access and data quality challenges encountered by the researcher in the field should not be divorced from their origins in the conflict. Similarly, research findings should be understood in relation to other major post-conflict narratives about the state of the nation or territory. By defining post-conflict contexts as meriting consideration as distinctive sites of work, this paper seeks to avoid 'de-contextualising' the discussion of research (Silkin and Hendrie, I997).

This analysis and the resultant framework are grounded in the authors' extensive experience of field research in Afghanistan and Timor-Leste, between 2009 and 2014, as well as in existing scholarship on the impacts of post-conflict and insecure environments on research. ${ }^{2}$ Kate Roll's research centred on Timorese ex-combatants and how the extension benefits programmes affected their relationship with the statefor examples of research drawing on the field work discussed here, see Roll (20I4, 20I8). During nine months of fieldwork, she pursued a mixed-methods approach, combining a national, representative randomised survey and qualitative interviews. The use of randomised survey sampling methods points up access issues as well as the rigidities of quantitative techniques, reflecting some of the challenges identified by Guba and Lincoln (I994) on competing paradigms and knowledge creation. Geoffrey Swenson (20I7, 20I8a, 20I8b) conducted in-depth, process tracing-based qualitative research with international and domestic actors engaged with both the state and non-state justice sectors in Afghanistan and Timor-Leste.

Both Timor-Leste in 2006-I4 and Afghanistan in 2009-I4 fit within the definition of Cohen and Arieli (2012). Afghanistan, while continuing to face an active insurgency, is still frequently conceptualised as post conflict in the sense that the postTaliban state-building project remains very much active and contested. Nevertheless, we realise that whether a country is 'in conflict' or is 'post conflict' cannot always be captured in this binary manner. In practice, conflict versus non-conflict often can be more accurately conceptualised as a spectrum. Again, while this paper concentrates on post-conflict situations, the challenges described here are not necessarily exclusive to such sites. They may overlap with those found in an authoritarian regime setting, those linked to conflict settings, and those identified in 'normal' settings. Frequently these problems are a matter of degree. Still, the cluster of issues discussed are found in post-conflict settings and are worth examining, and we believe that this label, however imperfect, will help to connect this work on access and quality with relevant scholars and practitioners.

\section{Access challenges}

The issue of inaccessibility - understood here as geographical areas that the researcher is unable or unwilling to enter-is one of the most salient features of research in post-conflict states. In addition, permission to speak with key informants or access to closed networks, which could be based on group affiliation, conflict experience, 
and gender, inter alia, also has to be negotiated. For the purposes of this paper, this dynamic is considered separately from the quotidian challenges of getting from point A to point B safely while taking into account the security of researchers, respondents, and research partners.

Researchers face access issues well before they reach the field. When designing research proposals, academic standards are balanced with university regulations and institutional review board (IRB) and insurer requirements, notably established in, and largely for, less complex environments. Even when researchers are willing to bear a large amount of risk, there are inherent limits, mostly established by IRBs, insurers, and relevant legislation. IRBs seek to 'protect the rights and welfare of subjects' (Amdur and Bankert, 20Io, p. 5). This role is undeniably important, although the manner in which it is executed often provokes controversy (Bosk and De Vries, 2004; Haggerty, 2004). Research is generally subjected to a cost-benefit analysis, and IRBs may have a significantly different calculus. The decisions of IRBs almost invariably have a (frequently dramatic) impact on the research design, the presentation of research, and even on whether research can be conducted at all in certain countries or regions. This dynamic is not exclusive to post-conflict settings, but given the inherently greater risks, it is more pronounced and restricts the ability of researchers to make their own determinations about the level of danger to internalise.

The matter of physical inaccessibility, meanwhile, stems from the post-conflict context, which commonly is typified by weak state institutions that struggle to provide security and repair infrastructure damaged during conflict (Brinkerhoff, 2005, p. 6); it can also be manufactured by a regime seeking to restrain the movement of researchers through bureaucratic controls and surveillance. Bridges, roads, and other essential transport mechanisms are often damaged by conflict, subject to unexpected closures, or poorly maintained. Civilian and dual-use infrastructure, including communications, electricity grids, and transportation, has increasingly become the target of bombing campaigns by the United States in conflict zones such as Afghanistan, Bosnia-Herzegovina, and Serbia (Thomas, 2006). Widely understood, but rarely acknowledged, poor infrastructure increases the time, difficultly, and cost of carrying out academic research. Other issues that can compound these access concerns include a lack of public infrastructure and the collapse of the private sector, creating logistical issues for the researcher, which make accessing those affected by conflict or the subject of a research sample even more difficult.

Crucially, scholars shape their research designs to address these constraints. Other researchers ultimately decide to focus on areas with better infrastructure, avoiding more isolated or remote regions, and forgo sampling methodologies that could necessitate travel to specific areas. Barakat and Ellis (I996, pp. I49-I50) note that research in conflict 'negate[s] the use of highly structured methods'. Supporting this finding in post-conflict settings, Roll found that poor transportation infrastructure was the main challenge to conducting a survey of former combatants in nine randomly selected sub-districts of Timor-Leste. Rural communities in this Southeast Asian nation are highly dispersed and infrastructure remains poor, reflecting the systematic 
destruction of roughly 70 per cent of the territory's infrastructure following the referendum on 30 August I999. In one instance, a community that was probably home to numerous selected former resistance members was cut off owing to flooding. Unwilling to leave her motorbike and make the journey on foot, this area was deemed 'inaccessible', resulting in the forfeiting of access to these respondents and damaging her sample. In a more extreme example of the trade-offs between logistical issues, security concerns, and the use of structured methods, Lyall, Blair, and Imai (20I3) underline the risks to enumerators in their 2013 survey on popular opinion in Afghanistan, during which one enumerator was injured. The inflexibility of such methods, whereby locations are preselected at random, makes it much more difficult for researchers to be flexible and responsive to changing conditions and circumstances.

Insecurity poses serious challenges for the design and execution of field studies more broadly. As with issues relating to transportation infrastructure, these challenges push researchers to work in more secure and accessible areas, a form of sampling bias. In a post-conflict context, this may involve issues ranging from high levels of crime, to concerns about sexual assault, to the risks posed by improvised explosive devices and roadblocks. In such situations, researchers have the ethical obligation to mitigate physical and psychological risks not only to themselves but also to their subjects and local research partners, including through careful site selection, taking protection of confidentiality seriously, and choosing secure venues. Nevertheless, meeting this standard entails costs and requires trade-offs. The more intensive are the security precautions, unsurprisingly, the less flexible and more conspicuous is the researcher. Visiting researchers may choose to travel in a convoy or be accompanied by guards or local research partners. Yet, these precautions can make other subjects, particularly victims, less comfortable and heighten concerns about confidentiality (Gill, 2004).

Female researchers, in particular, may confront problems pertaining to discrimination and safety, which are augmented in areas of insecurity and when working within often male-dominated conflict hierarchies. In particular, gender plays a complicated role in gaining access. Roll gained significant support from a high-ranking former resistance leader and official in part by agreeing to social engagements, in one case evening drinks at a beach restaurant_-something relatively standard and innocuous for a male researcher. However, this simple engagement raised concern about the expectation of intimacy and, if rebuffed, violence. The act of providing female company at the restaurant required recognition of the informant's status and masculine dominance. While authors such as Gurney (I99I, p. 379) describe how perceptions of women as 'warmer' improved their ability to gain access to some subjects, the vulnerability that comes from these feminine tropes must also be discussed (Huggins and Glebbeek, 2009; Rogers-Brown, 2015).

In Afghanistan, security was the most serious barrier to accessing respondents, namely those involved in the reconstruction of the justice sector. Security affected not only Swenson's ability to travel, but also his selection of research sites and ability 
to meet respondents. These concerns about security risks were well-founded: two significant suicide bombings occurred in Kabul during a research visit in February 20I4. The hotel where Swenson stayed on a previous trip was later attacked. Indeed, the 'safe' guesthouses and hotels frequently become insurgent targets owing to the high concentration of foreigners in them. Pervasive physical insecurity affected his research in various ways. Interview subjects were understandably reluctant to take risks to facilitate academic research. For instance, they were more hesitant to get together for interviews, the places and times deemed safe for meetings were limited, and transport to the interview site involved dangers for both the researcher and the respondent. Even in clearly post-conflict contexts, participation in research can put respondents at risk (Helbardt, Hellmann-Rajanayagam, and Korff, 20Io).

Swenson incorporated numerous context-driven steps in his research design and sampling methodology to mitigate risk and to access respondents. Reflecting the work of Tansey (2007) on process tracing and elite interviewing, he chose to use purposive chain referral sampling and to draw on pre-existing relationships rather than employ probabilistic sampling. The benefits of this type of sampling have been highlighted by other authors working in insecure environments. As Feenan (2002) argues, referred individuals are less likely to put the researcher at risk since he/she has already been vouched for by a mutual acquaintance. Reinforcing this finding, Swenson enjoyed considerable access to international and local NGOs and judicial actors due to overlapping social networks. Dependence on these sampling techniques does raise some concern. Certain associations may foster perceptions of partisanship and snowball or chain referral sampling methods increase the risk of the researchers failing to gather information from outside of a cohesive network, which often is interested in seeking to make its account of the conflict and its aftermath the authoritative one. Here, a researcher could easily find himself or herself with a decidedly lopsided sample, despite a commitment to a balanced approach.

Another way that security issues affected research design and sampling was the severe movement restrictions placed on potential respondents in Kabul. Consistently more accessible were those who worked for organisations with laxer rules regarding their movements. Owing to strict protocols, officials with embassies and international organisations were particularly limited in their mobility. Expatriate staff members were unable to leave their compounds for any non-essential official business. As a result, a key cohort of Kabul-based elites who were more accessible and who were able to identify and explain the activities and strategies implemented, became the focus of the research project. Interviews in the capital ably illuminated how judicial state-building efforts were designed, what they sought to achieve, and how Kabul-based domestic and international actors worked. In this manner, the research design and research questions were moulded by an awareness of who could or could not be accessed because of security concerns.

Barriers to movement may have explicitly political origins and purposes. Some states, especially authoritarian or semi-authoritarian ones, may have few qualms about intimidating researchers and research participants (Altbach, 200I; Clark, 2006). 
Officials hostile to research may seek to control and monitor researchers via demands for documentation and identity papers-bureaucratic technologies key to the state's regulation of movement - or by requiring researchers to seek approval for movement to certain areas (Torpey, I998). Roll was required to make time-consuming trips to district centres to meet with administrators as well as being tracked by the excombatants she was studying. At one point she was made to pull into the side of the road and was questioned extensively about her work, a show of force and a demonstration of the vitality of the resistance movement's intelligence networks, a decade after the cessation of conflict. The former fighter was concerned that she was operating in his commander's region without his consent; she had previously sought him out. The misunderstanding resolved, she was allowed to continue.

In Afghanistan, all foreigners were obliged to carry a Ministry of Interior-issued 'Foreijner,s (sic) Registration Card', issued on arrival, and requiring two passport photographs and a valid passport and visa. If the person entering the country does not have the photographs, they have to get them and take them to the Ministry of Interior to obtain the card. Moreover, enforcement is decidedly arbitrary. When Swenson was in Kabul in May 2009 and lost the card, his departure was almost denied. When leaving Kabul in February 20I4, the card was not even collected. Visitors can also be subject to harassment or a fine if they do not have their identity card. Researchers may find themselves subject to bribes or to demands for other forms of remuneration in exchange for access or assistance. Authoritarian tendencies by the state and the culture of repression may dissuade many from participating and generally hinder research.

Finally, while security risks and physical barriers, such as the loss of a bridge, are paradigmatic examples of access issues, access problems frequently are compounded by limited public- and private-sector development. Perhaps obvious, but it is worth noting that in the field, researchers cannot assume that they will be able to find potable water, reliable power, secure accommodation, dependable transportation, telephone credit, or easy access to food outside of less-afflicted or -isolated areas. Simple tasks such as purchasing food, finding safe accommodation, refuelling a motorbike, and making photocopies of survey forms necessitate planning. The economic distortion caused by a significant international presence in post-conflict states can render certain services, such as car rentals and translation, prohibitively expensive and force researchers to spend heavily on basic necessities such as accommodation and food, even within the context of great poverty (Chesterman, 2004, pp. 200-202).

This sectorial weakness permeates scholarly inquiry in subtle but important ways. Extended travel becomes more difficult, which increases the visiting researcher's dependence on the organisation or people with which he/she has engaged to assist or collaborate on the research. Researchers may have to assume increased risk. In Timor-Leste, for instance, no institutionalised banking services existed outside of the capital, Dili, and the country's second largest city, Baucau. Consequently, researchers needed to carry large amounts of cash, augmenting security concerns. Where accommodation is unavailable, researchers may choose to rely on local residents or 
religious establishments, introducing uncertainty and increasing stress; Roll stayed with nuns and priests throughout the countryside, owing to the lack of hotels. Technological changes, such as mobile banking, the use of tablet computers rather than printed survey forms, and the rapid extension of mobile networks and smartphone use, even in areas ravaged by conflict, have the potential to begin addressing such issues and improving coordination.

\section{Access biases and the capital city trap}

The problems with security and infrastructure, for example, are clear, but how do they affect research design and practice? More critically, how do they shape findings on post-conflict environments? In examining access, we discovered that these issues significantly shaped our research in Afghanistan and Timor-Leste; this was not 'business as usual'. In Timor-Leste, access issues created challenges for quantitative sampling. In Afghanistan, known security problems firstly shaped Swenson's research question and design, focusing his work on those in Kabul and leading to the use of chain referral sampling, and secondly further affected his access to those in the city. While quite diverse, these examples demonstrate how access issues exert pressure on the choice of research design, allowing the researcher to remain in relatively wellserviced and more secure population centres. Chambers (2006) describes this in the development literature as a 'capital city trap'; research in Afghanistan further underscores his observation that 'where there is a security problem, the hold of the capital city is even more severe' (Chambers, 2006, p. IO).

This matter is particularly acute in survey research. Even in probabilistic surveys, results may underrepresent highly isolated, rural populations, such as those in Roll's sample cut off from the larger towns during the rainy season. Of concern, this bias mirrors that of government teams from the capital who were disinclined to engage with populations beyond the reach of their $4 \times 4$ vehicles, reproducing the very bias under examination. What is more, the difficulty of accessing respondents made attaining a robust sample size difficult, reducing the utility and representativeness of the sample. This raises the basic question of in what circumstances are such quantitative methods simply inappropriate, at least in the absence of considerable institutional support. Problems with access in post-conflict environments create significant roadblocks, literal and figurative, to robust survey research. Sticking to the capital or struggling to achieve necessary sample sizes rules out large-n, geographically diverse sampling, which is vital for making broad-based, representative claims about populations.

Just as insecurity and transportation issues introduce sampling bias in quantitative research, Swenson's experience in Afghanistan underscores how these constraints can similarly shape research design, denying much room for hearing the voices of ordinary Afghans. How they experienced those activities thus fell outside of the scope of the research question. Claims about activities beyond the capital were difficult to verify. This experience reflects work by Kalyvas (2004, p. I66), who found 
that 'urban bias' promotes a 'general tendency to interpret phenomena a-contextually and in an exclusively top-down manner'. When access is limited, particularly to nonelite and rural or geographically distant informants, research designed to answer a compelling question risks becoming another voice in the echo chamber.

Many researchers tackle access issues by partnering with an established organisation. In cases where independent travel is prohibitively difficult because of poor physical infrastructure or insecurity, field researchers may work with NGOs, military organisations, development agencies, the United Nations, or even private-sector partners. Such entities maintain an established, on-the-ground presence in states such as Afghanistan and offer access to the vehicles needed to navigate degraded infrastructure. Such associations entail trade-offs (van der Haar, Heijmans, and Hilhorst, 2013), and may risk the researcher being seen as an extension of that body rather than independent. Further complicating such partnerships is the fact that NGOs often are invested in research outcomes and can be upset by assessments with which they do not agree. NGOs may also pursue advocacy research that serves their own ends and does not meet academic standards of impartiality and rigour (Black, 2003). ${ }^{3}$

At the same time, grey literature is making an important contribution. As described by Siliken and Hendrie (I997), the needs of NGOs for data may also drive and support innovative and rigorous research partnerships. NGO literature is helping policymakers, practitioners, and scholars alike to understand large-scale macro-level phenomena through ongoing series of reports on topics such as trends in global violence (Human Security Research Group, 20I3) and human development (United Nations Development Programme, 20I6). Furthermore, it is important to note that these are risks and not certainties. Even in very challenging circumstances, the work of international and local NGOs may be, and regularly is, of extremely high quality and addresses some crucial access issues by being able to capitalise on a long-term domestic presence and extensive local knowledge and contacts. For instance, the Asia Foundation has produced a methodologically rigorous national opinion survey annually since 2004, which has immense value for understanding contemporary Afghan society. The 2016 survey, for instance, 'polled I2,658 Afghan respondents, 52.7 per cent of whom were male and 47.4 per cent of whom were female, ${ }^{4}$ representing I6 ethnic groups from all 34 provinces in the country, including highly insecure areas (Asia Foundation, 20I6, p. 5). In Timor-Leste, the Judicial System Monitoring Programme (20I7) is an essential source of data and analysis on the state justice system nationwide.

Just as the capital city trap matters in development research, this bias also needs to be understood in post-conflict research. At the extreme, insecurity results in blind spots or known omissions when certain research areas are too dangerous to access in a manner consistent with social scientific research norms (Vlassenroot, 2006). While sensible and justified, the exclusion of particularly dangerous research sites affects the results and the knowledge gleaned. Certain people, particularly those isolated by conflict and those less prominent, powerful, or mainstream, will tend to be omitted. As other researchers make similar decisions, the marginality of such 
communities is reinforced and the voices of those who are better served-and studied-are amplified. The research that has been left undone must also be considered; decisions to avoid unsafe areas or topics that require access to former conflict actors come at the cost of more fully comprehending dynamics.

\section{Challenges to data quality}

Accessing individual respondents may be particularly difficult in post-conflict settings, yet a less acknowledged issue is that these environments also affect the quality of extant written records or government data and of the information that respondents offer. The effects on the quality of the data gathered in these locales is to be found in three main legacies of conflict:

- degraded information infrastructure;

- traumatisation and distrust; and

- low human capital.

It can be difficult, as Roll experienced, finally to locate a respondent, only to find him or her uncomfortable with the survey interview, or to gain access to records, only to discover that they are riddled with errors or omissions. Empathy is important here, as is an appreciation of the contextual reasons and the politics of why data quality is low. Ultimately, rethinking 'data quality' and working with the information provided may point to one way of resolving these problems.

The first key issue concerning data quality is that a post-conflict state's 'information infrastructure' may be degraded and characterised by systemic weakness. As Menkhaus (2004, p. 6) summarises: '[t] he poorer and more disrupted the society, the less likely reliable data will be available'. Simons and Zanker (20I2, p. I7) emphasise, meanwhile, that there exists a 'pronounced lack of state-sponsored statistical data for regions outside the industrialized world'. In Afghanistan, extensive internal conflict and the Taliban regime's hostility to non-religious-based legal order devastated the country's legal and broader informational infrastructure. In other cases, regimes may falsify data on sensitive subjects, increasing the unreliability of state statistics (Simons and Zanker, 20I2, p. I6). Often, furthermore, records are simply lacking, incomplete, or poorly organised, impacting on researchers. Without police data, for instance, it becomes difficult to analyse crime patterns; without census information, it is hard to understand demographic shifts or to compare subpopulations with the general population. For researchers hoping to use probability sampling, the absence of complete records to serve as sampling frameworks results in the lengthy and difficult process of constructing a framework or the use of 'second-best', non-probability sampling methods (Bøås and Hatløy, 2008, p. 35; Haer and Becher, 20I2, p. 4). Even when data are available, the quality may be poor. Such problems are increasingly acknowledged by researchers who use large datasets that seek to capture microlevel conflict dynamics (Eck, 20I2); they persist following a cessation of conflict. 
Records are deeply political and may be deliberately destroyed in conflict, as occurred in Timor-Leste, during the Indonesian withdrawal in October 1999 (The World Bank, 2009, p. 3). This pattern was repeated during the East Timorese crisis in 2006, with the Ministry of Finance's customs building targeted and burnt, allegedly with the purpose of destroying records (International Organization for Migration, $20 \mathrm{I} 2$, p. I8). Even if records are not destroyed systematically, data quality and control issues arise. The registry of Timor-Leste's Veterans' Pension Scheme, which formed the basis of Roll's sampling framework, was woefully out of date; approximately Io per cent of the individuals in the sampling frame were deceased. Ironically, however, this very same matter of poor data management facilitated access to the government's registry of registered former resistance members, critical for the study. Roll received the entire dataset on a USB (universal serial bus) drive from a database technician; protocols for acquiring such extensive, non-anonymous data would have been in place in contexts with more developed data protection. In this instance, poor data management facilitated academic access (while also raising ethical and data protection issues) and highlighted data quality issues. This dynamic exemplifies how matters of access and quality are not only intertwined, but also are not always clear-cut in their research implications. ${ }^{5}$

The second key issue with data quality, in this case with regard to information from interview or survey subjects, stems from distrust and trauma. Unsurprisingly, traumatisation has been documented in the psychological literature across a broad range of conflict settings, although its consequences still remain subject to debate (Pupavac, 2004; Robins, 20I2). Conducting field research in post-conflict environments frequently necessitates engagement with people who may have experienced and witnessed suffering, some of whom may also have partaken in violence. Such post-conflict trauma manifests as a 'variety of intrusive, avoidance, and hyperarousal symptoms and often [is] accompanied by heightened anxiety, depression, and hostility' (Pozhidaev and Andzhelich, 2005, p. 37). For researchers, concerns arise about the ability of traumatised subjects to recount their experiences reliably. These people may have difficulties recalling or discussing these topics, bolstering problems pertaining to item non-response (or insubstantial responses) and refusal to be interviewed. Working in such environments presents concerns about whether or not the information collected is accurate and complete, as well as broader ethical considerations regarding engagement with these subjects.

Respondents in post-conflict settings may be hesitant to answer questions and to interact with researchers. As Haer and Becher (20I2, p. 9) note, such 'non-response may be a coping strategy'. Löfving (2005, p. 89), too, sees 'lying, misinformation and direct silence' as essential to the 'communicative tool kit of people in politically unstable circumstances'. In circumstances where refusals, deflections, or silences may be protective, efforts to probe or penetrate these defences are ethically dubious. Interviewing traumatised persons also raises concerns about re-traumatisation, by which the act of recounting distressing histories endangers the respondent, causing him or her to 'relive' the episode (Bell, 20oI). This risk calls to mind Anderson's 
(I999) call to 'do no harm' in humanitarian, development, and research practice, underscoring the ethical imperative for research not to abuse participants. The spectre of re-traumatisation has the effect of discouraging work on particularly sensitive subjects. Jessee (20I I, p. 288), for instance, states that her research process was 'impeded at every step by [a] desire to minimize harm for my informants'. This same concern led Roll to avoid putting extensive life-history questions to Timorese former resistance members, despite their research value, choosing instead to focus on the postconflict period.

In post-conflict contexts, subjects may be particularly unwilling to trust foreign researchers, compromising data quality and influencing whether respondents participate at all (Groger, Mayberry, and Straker, I999). This is a reasonable position. Many post-conflict states emerged from colonial and neo-colonial interventions, which drew power from the 'study' of subjects and the management of data (Appadurai, I993). ${ }^{6}$ Subjects may distrust researchers' ability to protect their anonymity, particularly if recordings or notes are being made (Gokah, 2006, p. 68). Feenan (2002, p. I55) describes how his efforts to be transparent and to share information with his paramilitary subjects in Northern Ireland had the potential of backfiring, leading to apprehension that he would not be able to maintain confidentiality. Negative triggers can be difficult to predict: one respondent in Timor-Leste was distressed by the use of a red pen, pointing out that Indonesian officials had used them in certain records. Others are more obvious: associations with one conflict party may reduce the willingness of respondents to participate. As Cohen and Arieli (20I I, p. 420) reflect, their experience as Israeli-Jewish researchers 'amplified the need for a basis of trust in accessing the Palestinian and Jordanian research population and enlisting its cooperation'. Goodhand (2000, p. I2) underlines that such research 'occurs within an intensely political environment and is unlikely to be viewed by local actors as neutral or altruistic'. The appearance of partisanship is consequential, easy to acquire, and difficult to shake in post-conflict environments. ${ }^{7}$

Elite actors may have other reasons for deciding not to participate or to offer incomplete information. They tend to be interested in the 'official' knowledge that the researcher produces; research consistent with their views and the imprimatur of a foreign university can be used as a potential source of legitimacy for their position both domestically and internationally. International NGOs are by no means immune to this dynamic as they seek to create their own narratives, and researchers of all backgrounds should be attuned to these issues. NGOs in post-conflict settings, like NGOs more generally, face pressure to secure donor funds (Cooley and Ron, 2002). Consequently, they are incentivised to try to shape the dominant narratives in the areas in which they work to ones that are favourable to their issue areas, strategic approach, and programming (Cohen and Green, 20I2). When conducting elite interviews with international and domestic actors working on state-building issues, Swenson found that they were almost always quick to acknowledge flaws within the state-building process, but equally swift in distancing their own work and approach from the larger problems. NGOs often have strong reasons to downplay problems 
and to magnify successes as 'they must justify their existence to donors, secure new contracts, and fend off competitors' (Cooley and Ron, 2002, pp. 37-38). These concerns proved well founded as some practitioners responded very negatively to published criticism of their programme (Bartz, Momand, and Swenson, 2018). Researchers need to recognise this dynamic in their dealings with these entities.

The third driver of poor data quality in post-conflict settings is low levels of human capital or education, increasing the challenge of eliciting robust responses from research subjects. A major social legacy of conflict may be the destruction or suspension of institutions that provide education and training - on the devastating impact of the Afghanistan conflict on legal education, for example, see Swenson and Sugerman (2OI I). In addition, data quality issues also arise in relation to survey responses, probably reflecting a combination of extremely low education levels as well as distrust and trauma. In Roll's experience, subjects in Timor-Leste at times had difficulties recalling or discussing their experiences, fortifying problems with item non-response and affecting overall data quality. This reticence in part reflects unfamiliarity with survey instruments and low educational levels. Forty-six per cent of respondents were illiterate and 33 per cent had received no schooling; these high rates reflect the deprivation and disruption that marked former fighters' lives during the conflict. Even though surveys were researcher-administered, which can address some matters pertaining to literacy, comprehension, and in some instances survey fatigue, these aspects required the dramatic simplification of survey itemsat the cost of sophistication, abstraction, and some types of comparative analysis. Yet, the researcher must also remain vigilant to ensure that survey questions are not unclear or even culturally unintelligible by reflecting a set of assumptions disconnected from respondents' lived reality.

\section{Data quality and study bias}

Data availability and quality issues need to be taken into account when designing field research in post-conflict settings, as well as when thinking critically about the position of both respondents and the researcher in the post-conflict political environment. Low education levels and a lack of national data necessarily affect the research design and the choice of methodology. Similarly, as discussed above, a paucity of public records and government data can cause problems for comparative analysis or introduce dataset biases into large-n comparative studies. Just as data quality issues can affect quantitative research, economic and socio-political factors that typify the post-conflict context can increase the stakes for participants. Researchers must remain aware of the risk that their work poses to participants and ensure, as always, that consent is fully informed (Romano, 2006). However, the motivations of participants also need to be understood: individuals who opt to participate may be nonrepresentative in their willingness to take above-average risks to have their voices heard in these repressive circumstances. Alternatively, participants may tend to be more favourable to the government as they have less reason to be fearful. 
Taken collectively, these data quality issues incentivise certain methodological choices and 'fixes', which may introduce certain biases into research conducted in post-conflict environments. Researchers are faced with the choice of whether or not to gather and use 'bad data' (such as incomplete datasets or testimonies rife with non-response bias) or to concentrate on narrower but more robust sources, often elite informants. Problems concerning trust and low human capital, as described above, increase researchers' reliance on elite respondents who are willing to take part in research and to provide 'good' or usable data more readily. This is not surprising as elite subjects are more easily identifiable and relatively accessible, frequently have a greater stake in the research and thus are more likely to participate, are more likely to understand the type of data researchers look to acquire, and speak in a language that the researcher understands (or conversely be more comfortable working with a translator). As with access issues, the risk is the perpetuation of 'top-down' understandings of conflict. These problems can be addressed, but doing so regularly requires modification of the scope or focus of the research.

One way forward is to engage constructively with 'bad data'. For instance, finding victims' narratives replete with historical inaccuracies during her fieldwork in Rwanda, Fujii (20I0) examines how these accounts remain useful and the importance of metadata-rumour, denials, and silences - in yielding insights. She notes that these ambiguities and the application of 'bad data' have yet to be fully explored in the political science literature (Fujii, 20Io, p. 239). Working with respondents who have suffered trauma, are distrustful, or are unfamiliar with research practice necessitates additional time, effort, and resources, as well as a willingness to listen to and recognise the value of unconventional narratives. Engaging with these 'flawed' accounts is a counterpoint to dominant, elite narratives, but also introduces difficulties regarding evaluating competing claims and incorporating radically different types of information. This is made all the more difficult by the fact that engaging in triangulation, process tracing, and other techniques designed to produce the most reliable narratives are more difficult to undertake, and, in the context of working with metadata, for example, may not be appropriate. Here, elite bias in research on post-conflict states is not only about data quality, but also about the system of epistemology that determines what information is useful.

\section{Discussion}

By systematically highlighting the challenges to access and data quality in postconflict states, this paper is not seeking to discourage research in those settings, but rather to improve it. The creation of a framework to explore the effects of postconflict environments on research methods is intended to help researchers of all types preparing for fieldwork in communities that are not their own to consider the ways in which these places are distinct. In other words, Afghanistan is not Austria. Methods that are considered standard best practice for social science scholarship in 
relatively stable, developed countries will be more difficult, expensive, and timeconsuming in post-conflict nations. The classic trade-off among time, resources, and quality becomes amplified. Below are some possible ways forward.

A first step is to look for ways to work against the constraints that the field introduces, most notably elite and capital city biases. Chambers (2006) offers techniques for addressing these issues across a wide range of research locales. These may involve entering into partnerships with NGOs, governments, or other organisations to enhance mobility, examining different sampling techniques that increase heterogeneity, or simply allotting more time to field research to deepen relationships and to gain a better understanding of the post-conflict context. Addressing these issues thus entails a greater commitment by scholars, academic departments, and funding bodies to according the necessary time and additional resources for research to be carried out in these complex areas.

A practical way to tackle some of these issues is for academic researchers to learn from how NGOs operate in the field, namely as teams. This dynamic can aid the incorporation of diverse perspectives and potentially mitigate the risk that the researcher becomes an unduly biased participant in domestic and international contests over the production of authoritative accounts of the conflict and its aftermath. Team-based research can help to address elite or exclusionary power relations that are reproduced through the separation of 'outsider' and 'local' knowledge. A principal advantage of this approach is the expansion of the boundaries of the field, both by reducing the insecurity and stress experienced by lone researchers and by improving access and data quality through greater demographic, linguistic, and gender balance in the team.

Yet, these methodological and logistical fixes are, as this paper has underscored, difficult to apply with good reason. They stem directly from the constraints of the field. As such, a more radical, step towards bettering research practice in postconflict settings is to recognise that they are unique and to foreground how the environments have shaped research design and practice, as well as how data have been generated. The effort to catalogue issues of access and data quality is driven by the need to enhance understanding of the 'known unknowns' of research. Such work is part of a larger project to develop an epistemology of fieldwork in postconflict environments, with deeper consideration of what constitutes 'good' research in terms of methodology and evidence in these complex settings. This depends on comprehending how the research contexts influence how one approaches data and data collection.

The need for flexibility and improvisation has been at the heart of much advice on research in conflict zones, and this points to a quite different approach to research than is generally taught on research design courses or disciplined through the use of research and ethics approval processes. More highly structured methodologies, such as case quantitative surveys, pose particular problems in these environments, raising the fundamental question of how to introduce flexibility into methodologies that only gain validity through precise application. There is ample scope for applying 
the lessons of participant-driven research to quantitative survey research. This approach might improve data quality by making prominent the needs of the respondent and the context in which the respondent is residing. This question thus remains open and a potential subject for further research.

Finally, one sees expansion of the space in which researchers can operate and experimentation with remote techniques. For instance, the use of mobile technology for surveys and remuneration could redefine who is accessible and who is inaccessible following a conflict. However, remote access invariably produces different insights than actually being present. Technologies will continue to transform fieldwork and data collection-tablet devices are replacing paper surveys, and mobile telephones have widely replaced radios; work needs to continue on the drivers of this change and the effects.

\section{Conclusion}

Post-conflict transitions and settings are a diverse yet distinct subject of study, which constitute a vital area of inquiry. While this work on access and data quality has been drawn from the authors' experiences as academic researchers, these issues are also highly relevant to practitioners as creators and consumers of research. Research on post-conflict life, institutions, and politics is of immense importance to those states affected by conflict and broader efforts to promote international security and development, as well as to policymakers and practitioners seeking to learn lessons from past experiences (Stone, I989). Academic and NGO researchers influence how the post-conflict order is understood and ultimately how it is conceptualised by policymakers. Studying post-conflict environments is innately challenging and those difficulties have important consequences for how research is designed and performed: the post-conflict environment affects how one studies and thus understands postconflict states.

This conclusion that the research context affects the practice of research, including its design and execution, appears straightforward. However, if one extends this to the subject of knowledge production, the conclusion is of additional importance. This work has set forth to identify and describe the core challenges to data access and quality during fieldwork in post-conflict contexts and begun to link them to the modifications that researchers make, and which ultimately are reflected in the research that they produce. Exploring these challenges suggests that this situation benefits from transparency of the research's limitations, which includes not only disclosing with whom the researcher talked, but also with whom he/she choose not to speak, or were not able to interview and why. Interrogation of the challenges posed by the field may not resolve these issues, but it may help to establish the 'known unknowns'.

The idea that methodology can exist independent of context is one of the common fallacies of the research methods courses that are taught across universities. In contexts that differ so greatly from those in which methods were developed, such as 
social science household surveying, there needs to be a new way of thinking about what good research means. Research in post-conflict environments is not 'business as usual'. Substantive access and data quality issues are intrinsic to research in postconflict settings, and, as such, they are woven into the fabric of all research that is conducted in such complex spaces. This paper should be seen as a continuation of a broader conversation on how researchers should think about research design, practice, and bias when conducting fieldwork in dynamic and sometimes hostile environments.

\section{Acknowledgements}

The authors would like to thank Meghan Campbell, Richard Caplan, and John Gledhill for their feedback on earlier drafts of this paper. They also appreciate the constructive comments of the three anonymous peer reviewers and the editors of the journal.

\section{Correspondence}

Dr Geoffrey Swenson, Lecturer, Department of International Politics, City, University of London, Northampton Square, London, ECIV oHB, United Kingdom.

E-mail: geoffrey.swenson@city.ac.uk

\section{Endnotes}

I The work of Menkhaus (2004) for Interpeace, an international peace-building NGO, on tools for measuring post-conflict impacts is but one example.

2 While this study draws most heavily on academic work conducted by the authors, both also have experience as researchers within NGOs, and this framework is broadly applicable to a non-academic research audience.

3 This may also apply to governmental partnerships, as highlighted by Mosse (2006).

4 That the total does not add up to Ioo.o per cent most probably is because of rounding.

5 Thanks to one of the anonymous peer reviewer for pointing out this interesting dynamic.

${ }^{6}$ Romano (2006) highlighted issues with anti-Western sentiment while conducting research in the Middle East. Researchers may find it difficult to distinguish their own work and political orientation from that of their home country or institution.

7 Non-participation and misrepresentation pose challenges, but the manner in which they occur may provide a useful type of metadata in and of itself.

\section{References}

Altbach, P.G. (200I) 'Academic freedom: international realities and challenges'. Higher Education. 4I(I-2). pp. 205-219.

Amdur, R.J. and E.A. Bankert (20I0) Institutional Review Board: Member Handbook. Jones and Bartlett Learning, Sudbery, MA. 
Anderson, M.B. (1999) Do No Harm: How Aid Can Support Peace-Or War. Lynne Rienner Publishers, Boulder, CO.

Angucia, M., J. Zeelen, and G. de Jong (2010) 'Researching the reintegration of formerly abducted children in northern Uganda through action research: experiences and reflections'. Journal of Community and Applied Social Psychology. 20(3). pp. 217-23I.

Appadurai, A. (I993) 'Number in the colonial imagination'. In C.A. Breckenridge and P. van der Veer (eds.) Orientalism and the Postcolonial Predicament: Perspectives on South Asia. University of Pennsylvania Press, Philadelphia, PA. pp. 3I4-340.

Asia Foundation (2016) A Survey of the Afghan People: Afghanistan in 2016. Asia Foundation, Kabul.

Autesserre, S. (2012) 'Dangerous tales: dominant narratives on the Congo and their unintended consequences'. African Affairs. III (443). pp. 202-222.

Barakat, S. and S.U.E. Ellis (I996) 'Researching under fire: issues for consideration when collecting data and information in war circumstances, with specific reference to relief and reconstruction projects'. Disasters. 20(2). pp. I49-I56.

Bartz, E., K. Momand, and G. Swenson (2018) 'Correspondence: debating the rule of law in Afghanistan'. International Security. 43(I). pp. I8I-I85.

Bell, P. (200I) 'The ethics of conducting psychiatric research in war-torn contexts'. In M. Smyth and G. Robinson (eds.) Researching Violently Divided Societies: Ethical and Methodological Issues. United Nations Press, New York, NY. pp. I84-I92.

Black, R. (2003) 'Ethical codes in humanitarian emergencies: from practice to research?'. Disasters. 27(2). pp. 95-I08.

Bøås, M. and A. Hatløy (2008) “'Getting in, getting out”: militia membership and prospects for re-integration in post-war Liberia'. The Journal of Modern African Studies. 46(I). pp. 33-55.

Bosk, C.L. and R.G. De Vries (2004) 'Bureaucracies of mass deception: institutional review boards and the ethics of ethnographic research'. The Annals of the American Academy of Political and Social Science. 595(I). pp. 249-263.

Brinkerhoff, D.W. (2005) 'Rebuilding governance in failed states and post-conflict societies: core concepts and cross-cutting themes'. Public Administration and Development. 25(I). pp. $3^{-1} 4$.

Bush, K. and C. Duggan (2013) 'Evaluation in conflict zones: methodological and ethical challenges'. Journal of Peacebuilding and Development. 8(2). pp. 5-25.

Carpenter, C. (20I2) "'You talk of terrible things so matter-of-factly in this language of science": constructing human rights in the academy'. Perspectives on Politics. Iо (2). pp. 363-383.

Chambers, R. (2006) Poverty Unperceived: Traps, Biases and Agenda. IDS Working Paper 270. July. Institute of Development Studies, Brighton.

Chesterman, S. (2004) You, the People: The United Nations, Transitional Administration, and State-Building. Oxford University Press, Oxford.

Clark, J.A. (2006) 'Field research methods in the Middle East'. PS: Political Science and Politics. 39 (3). pp. 4I7-424.

Cohen, D.K. and A.H. Green (2012) 'Dueling incentives: sexual violence in Liberia and the politics of human rights advocacy'. Journal of Peace Research. 49 (3). pp. $445^{-458}$.

Cohen, N. and T. Arieli (20I I) 'Field research in conflict environments: methodological challenges and snowball sampling'. Journal of Peace Research. 48(4). pp. 423-435.

Collier, P. and A. Hoeffler (2006) 'Military expenditure in post-conflict societies'. Economics of Governance. 7(I). pp. 89-107.

Cooley, A. and J. Ron (2002) 'The NGO scramble: organizational insecurity and the political economy of transnational action'. International Security. 27(I). pp. 5-39.

Eck, K. (20I2) 'In data we trust? A comparison of UCDP GED and ACLED conflict events datasets'. Cooperation and Conflict. 47(I). pp. I24-I4I. 
Feenan, D. (2002) 'Researching paramilitary violence in Northern Ireland'. International Journal of Social Research Methodology. 5(2). pp. I47-I63.

Fujii, L.A. (2010) 'Shades of truth and lies: interpreting testimonies of war and violence'. Journal of Peace Research. 47(2). pp. 23I-24I.

Gill, H. (2004) 'Finding a middle ground between extremes: notes on researching transnational crime and violence'. Anthropology Matters. 6(2). pp. I-9.

Gokah, T. (2006) 'The naïve researcher: doing social research in Africa'. International Journal of Social Research Methodology. 9(I). pp. 6I-73.

Goodhand, J. (2000) 'Research in conflict zones: ethics and accountability'. Forced Migration Review. $8(4)$. pp. I2-I6.

Groger, L., P.S. Mayberry, and J.K. Straker (I999) 'What we didn't learn because of who would not talk to us'. Qualitative Health Research. 9(6). pp. 829-835.

Guba, E.G. and Y.S. Lincoln (I994) 'Competing paradigms in qualitative research'. In N.K. Denzin and Y.S. Lincoln (eds.) Handbook of Qualitative Research. Sage Publishing, Thousand Oaks, CA. pp. IO5-II7.

Gurney, J.N. (I99I) 'Female researchers in male-dominated settings: implications for short-term versus long-term research'. In M. Pogrebin (ed.) Qualitative Approaches to Criminal Justice: Perspectives from the Field. Sage Publishing, London. pp. 377-383.

Haer, R. and I. Becher (2OI2) 'A methodological note on quantitative field research in conflict zones: get your hands dirty'. International Journal of Social Research Methodology. I5 (I). pp. I-I3.

Haggerty, K.D. (2004) 'Ethics creep: governing social science research in the name of ethics.' Qualitative Sociology. 27(4). pp. 39I-4I4.

Helbardt, S., D. Hellmann-Rajanayagam, and R. Korff (20I0) 'War's dark glamour: ethics of research in war and conflict zones'. Cambridge Review of International Affairs. 23 (2). pp. 349-369.

Huggins, M.K. and M.L. Glebbeek (eds.) (2009) Women Fielding Danger: Negotiating Ethno-graphic Identities in Field Research. Rowman and Littlefield Publishers, Inc., Lanham, MD.

Human Security Research Group (2013) Human Security Report 2013: The Decline in Global ViolenceEvidence, Explanation and Contestation. Simon Fraser University and Human Security Press, Vancouver. International Organization for Migration (2012) Ending the 2006 Internal Displacement Crisis in Timor-Leste: Between Humanitarian Aid and Transitional Justice. International Organization for Migration, Geneva.

Jessee, E. (2OII) 'The limits of oral history: ethics and methodology amid highly politicized research settings'. Oral History Review. 38(2). pp. 287-307.

Judicial System Monitoring Programme (2017) Overview of the Justice Sector 2016. Judicial System Monitoring Programme, Dili.

Kalyvas, S.N. (2004) 'The urban bias in research on civil wars'. Security Studies. I3 (3). pp. I60-I90.

Kühn, F.P. (2016) 'The ambiguity of things: souvenirs from Afghanistan'. Journal of Intervention and Statebuilding. IO (I). pp. 97-II5.

Löfving, S. (2005) 'Silence and the politics of representing rebellion: on the emergence of the neutral Maya in Guatemala'. In P. Richards (ed.) No Peace No War: An Anthropology of Contemporary Armed Conflicts. Ohio University Press, Athens, OH. pp. 77-97.

Lyall, J., G. Blair, and K. Imai (20I3) 'Explaining support for combatants during wartime: a survey experiment in Afghanistan'. American Political Science Review. ro7(4). pp. 679-705.

Menkhaus, K. (2004) Impact Assessment in Post-conflict Peacebuilding. Interpeace, Geneva.

Mosse, D. (2006) 'Anti-social anthropology? Objectivity, objection, and the ethnography of public policy and professional communities'. Journal of the Royal Anthropological Institute. I2 (4). pp. 935-956.

Nordstrom, C., and A.C. Robben (I995) Fieldwork under Fire: Contemporary Studies of Violence and Survival. University of California Press, Berkeley, CA.

Pozhidaev, D. and R. Andzhelich (2005) Beating Swords into Plowshares. Reintegration of Former Combatants in Kosovo. Center for Political and Social Research, Pristina. 
Pupavac, V. (2004) 'Psychosocial interventions and the demoralization of humanitarianism'. Journal of Biosocial Science. 36(4). pp. 49I-504.

Richards, P. (2005) 'New war: an ethnographic approach'. In P. Richards (ed.) No Peace, No War: An Anthropology of Contemporary Armed Conflicts. Ohio University Press, Athens, OH. pp. 77-97.

Robins, S. (2012) 'Challenging the therapeutic ethic: a victim-centred evaluation of transitional justice process in Timor-Leste'. International Journal of Transitional Justice. 6(I). pp. 83-IO5.

Rogers-Brown, J. (2015) 'More than a war story: a feminist analysis of doing dangerous fieldwork'. In V. Demos and M.T. Segal (eds.) At the Center: Feminism, Social Science and Knowledge. Advances in Gender Research. Volume 20. Emerald Group Publishing Limited, Bingley. pp. II I-I3I.

Roll, K. (2OI4) 'Encountering resistance: qualitative insights from the quantitative sampling of excombatants in Timor-Leste'. PS: Political Science and Politics. 47(2). pp. 485-489.

Roll, K. (2018) 'Street level bureaucrats and post-conflict policy-making: corruption, correctives, and the rise of veterans' pensions in Timor-Leste'. Civil Wars. 20(2). pp. 262-285.

Romano, D. (2006) 'Conducting research in the Middle East's Conflict Zones'. PS: Political Science and Politics. 39(3). pp. 439-44I.

Schmidt, B. and I. Schröder (200I) Anthropology of Violence and Conflict. Routledge, London.

Silkin, T. and B. Hendrie (1997) 'Research in the war zones of Eritrea and northern Ethiopia'. Disasters. $2 \mathrm{I}(2)$. pp. I66-I76.

Simons, C. and F. Zanker (2012) Finding the Cases that Fit: Methodological Challenges in Peace Research. Working Paper 189. March. German Institute of Global and Area Studies, Hamburg.

Stone, D.A. (1989) 'Causal stories and the formation of policy agendas'. Political Science Quarterly. I04(2). pp. 28I-300.

Swenson, G. and E. Sugerman (20II) 'Building the rule of law in Afghanistan: the importance of legal education'. Hague Journal on the Rule of Law. 3(I). pp. I30-I46.

Swenson, G. (2017) 'Why US efforts to promote the rule of law in Afghanistan failed'. International Security. 42 (I). pp. II4-ISI.

Swenson, G. (2018a) 'Legal pluralism in theory and practice'. International Studies Review. 20 (3). pp. 438-462.

Swenson, G. (20I8b) 'The promise and peril of paralegal aid'. World Development. Io6 (June). pp. 5I-63.

Tansey, O. (2007) 'Process tracing and elite interviewing: a case for non-probability sampling'. PS: Political Science and Politics. $40(4)$. pp. 765-772.

The World Bank (2009) Timor-Leste: Country Environmental Analysis. The World Bank, Washington, DC.

Thomas, W. (2006) 'Victory by duress: civilian infrastructure as a target in air campaigns'. Security Studies. I5(I). pp. I-33.

Torpey, J. (1998) 'Coming and going: on the state monopolization of the legitimate "means of movement”. Sociological Theory. I6(3). pp. 239-259.

van der Haar, G., A. Heijmans, and D. Hilhorst (2013) 'Interactive research and the construction of knowledge in conflict-affected settings'. Disasters. 37(SI). pp. S20-S35.

Vlassenroot, K. (2006) 'War and social research: the limits of empirical methodologies in war-torn environments'. Civilisations. 54(I-2). pp. I9I-I98.

United Nations Development Programme (2016) Human Development Report 2016: Human Development for Everyone. United Nations Development Programme, New York, NY. 